Titulo do Trabalho

\title{
ANÁLISE MORFOMÉTRICA DA MICROBACIA DO CÓRREGO DO VANGASSE - PRATÂNIA/SP
}

Nome do Autor (a) Principal

Mikael Timóteo Rodrigues

Nome (s) do Coautor (a) (s)

Yara Manfrin Garcia; Bruno Timóteo Rodrigues

Nome (s) do Orientador (a) (s)

Lincoln Gehring Cardoso

Instituição ou Empresa

Universidade Estadual Paulista "Julio de Mesquita Filho" - UNESP/FCA, Botucatu.

E-mail de contato

mikaelgeo@gmail.com

Palavras-chave

Bacia hidrográfica, parâmetros físicos, hidrologia.

\section{INTRODUÇÃO}

No Brasil, a unidade física adotada na legislação para o gerenciamento de recursos hídricos é a de bacia hidrográfica que constitui um principio básico para a implementação da gestão dos recursos hídricos sendo utilizada em vários países. 
Christofoletti (1974) define bacia hidrográfica como a área drenada por um determinado rio ou por um sistema fluvial, funcionando como um sistema aberto.

A bacia hidrográfica é como um conjunto de terras drenadas por um rio e seus afluentes, formada nas regiões mais altas do relevo por divisores de água, onde as águas das chuvas, ou escoam superficialmente formando os riachos e rios, ou infiltram no solo para formação de nascentes e do lençol freático (CARDOSO, 2012). Esses divisores de águas separam uma bacia da outra e, internamente, existem elevações que são denominadas de interflúvios, que dividem sub-bacias hidrográficas. Politano \& Pissarra (2003) destacam que as bacias, sub-bacias e microbacias hidrográficas constituem os ecossistemas adequados para avaliação dos impactos causados pela atividade antrópica e que a subdivisão de uma bacia em microbacias permite a pontualização de problemas, tornando mais fácil a identificação de focos de deterioração dos recursos naturais e do grau de comprometimento da produção existente.

Quando se refere as bacias hidrográficas, são vários os parâmetros que podem ser analisados. Segundo Lima (2008) alguns deles são aplicáveis à bacia como um todo, enquanto que outros relativos a apenas algumas características do sistema.

No presente trabalho, serão analisados apenas alguns dos parâmetros físicos citados anteriormente ou mais especificamente, serão apresentados os resultados da análise morfométrica. Para Siqueira (2012) os estudos morfométricos das redes de drenagem em bacias hidrográficas são fundamentais na caracterização de suas potencialidades e limitações quanto ao seu uso, favorecendo o planejamento adequado das atividades a serem desenvolvidas, através dos diagnósticos e análise dos riscos de degradação dos recursos naturais. A análise morfométrica, entendida como 0 levantamento de índices numéricos que classificam as redes de drenagem, auxilia nos estudos de erosão, pois possibilita avaliar o grau de energia e a susceptibilidade de ocorrência de processos erosivos e o comportamento da microbacia ao longo de sua drenagem. 


\section{OBJETIVO GERAL}

O presente trabalho teve como objetivo realizar a caracterização morfométrica da microbacia do Córrego do Vangasse, localizado no município de Pratânia/SP.

\section{METODOLOGIA}

Este trabalho foi realizado na microbacia do Córrego do Vangasse (Figura 1), localizada no município de Pratânia/SP, com uma área de 12, 81 km² e 15,376 km.

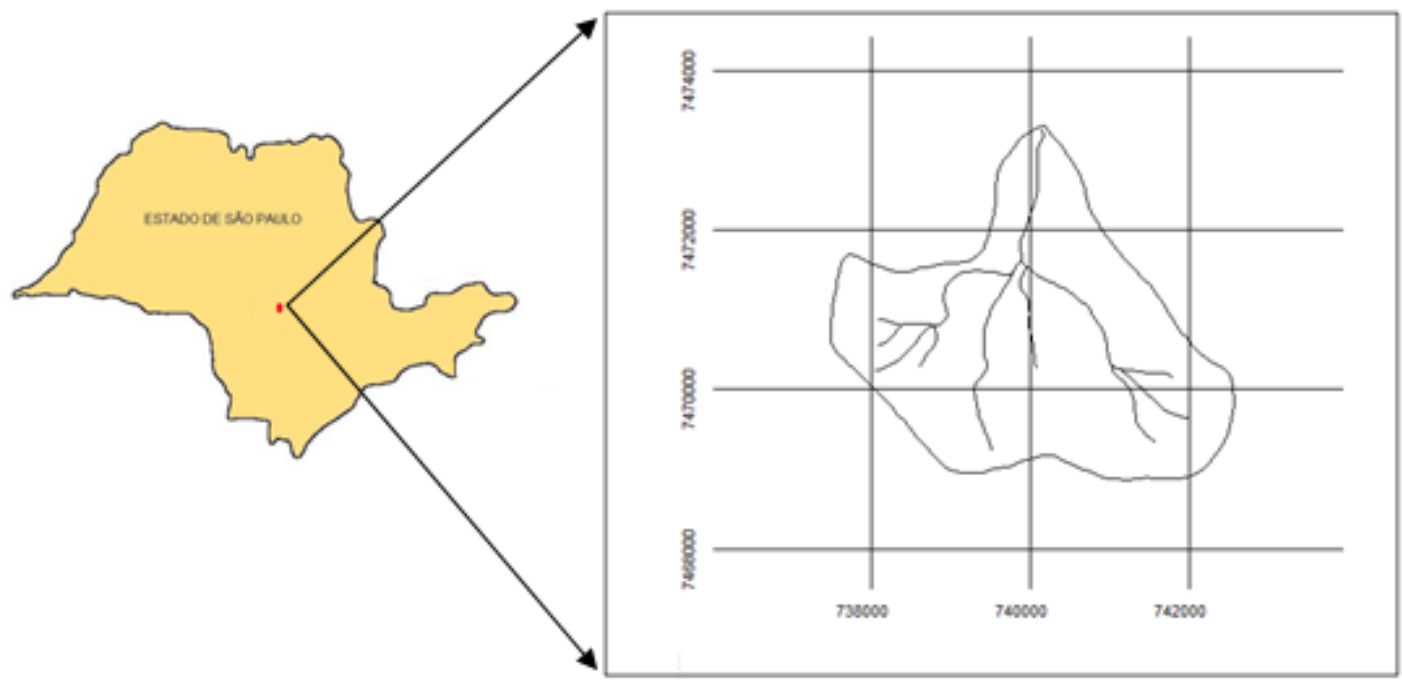

Figura 1 - Localização da microbacia do Córrego do Vangasse

A delimitação da microbacia hidrográfica foi obtida através do divisor topográfico, utilizando a Carta Topográfica de Pratânia, editada pelo Instituto Brasileiro de Geografia e Estatística- IBGE (1973), em escala de 1:50.000, folha de nomenclatura SF-22-Z-B-V-4 para isso, foi utilizado o Sistema de Informação Geográfica IDRISI e o Cartalinx, sendo o primeiro para georreferenciar e o segundo, para delimitar a bacia e a rede de drenagem. A área e o perímetro após delimitação do contorno da microbacia foram medidas através 
do comando "Area" e "Perim" do menu "Database Query", pertencente ao módulo "Gis Analysis" do Idrisi e também, para verificação, através de uma mesa digitalizadora.

Quanto aos parâmetros analisados, eles consistem na área de drenagem, fator de forma, coeficiente de compacidade, sistema de drenagem, densidade de drenagem e a extensão média do escoamento superficial.

\section{RESULTADOS}

Os resultados obtidos na análise morfométrica da microbacia do Córrego Vangasse encontra-se na Tabela 1. De acordo com a classificação de rios, segundo Sthraler (1957), a microbacia é de $3^{a}$ ordem, e apresenta poucas ramificações.

Tabela 1 - Parâmetros Analisados

\begin{tabular}{l|c}
\hline Parâmetro & Dimensões \\
\hline Área & $12,81 \mathrm{~km}$ \\
\hline Perímetro & $15,376 \mathrm{~km}$ \\
\hline Coeficiente de Compacidade (Kc) & $1,20 \mathrm{~km}$ \\
\hline İndice de Circularidade (Ic) & $0,68 \mathrm{~km}$ \\
\hline Fator Forma (Kf) & $0,62 \mathrm{~km}$ \\
\hline Densidade de Drenagem (Dd) & $1,07 \mathrm{~km}$ \\
\hline Densidade Média da Bacia Hidrográfica & $2,53 \%$ \\
\hline Sinuosidade do Curso Principal & $1,12 \mathrm{~km}$ \\
\hline Extensão Média do Escoamento Superficial & $1,37 \mathrm{~km}$ \\
\hline
\end{tabular}

O comprimento do canal principal é de $4,56 \mathrm{~km}$. A densidade de drenagem é de $1,07 \mathrm{~km}$, indicando dessa forma que a microbacia possui uma baixa capacidade de drenagem.A densidade de drenagem é um fator importante na indicação do grau de desenvolvimento do sistema de drenagem de uma bacia. Sendo assim,este índice, fornece uma indicação da eficiência da drenagem da bacia, sendo expressa pela relação 
entre o somatório dos comprimentos de todos os canais da rede; sejam eles perenes, intermitentes ou temporários; e a área total da bacia (ANTONELI; THOMAZ, 2007).

Christofoletti (1969) destaca que valores menores que $7,5 \mathrm{~km} / \mathrm{km}^{2}$ apresentam baixa densidade de drenagem. Valores entre 7,5 e $10,0 \mathrm{~km} / \mathrm{km}^{2}$ apresentam média densidade. Já valores acima de $10,0 \mathrm{~km} / \mathrm{km}^{2}$, apresentam alta densidade hidrográfica. A bacia em estudo apresenta baixa densidade de drenagem, ou seja, apresenta um relevo pouco declivoso com rampas longas e solos profundos com alta capacidade de infiltração, exceto nas áreas próximas a foz, onde o relevo apresenta vertentes curtas e declivosas.

Já de acordo com Villela e Mattos (1975), esse mesmo índice (densidade de drenagem), pode variar de $0,5 \mathrm{~km} / \mathrm{km}^{2}$ em bacias com drenagem pobre, a $3,5 \mathrm{~km} / \mathrm{km}^{2}$, ou mais, em bacias bem drenadas, indicando, também, que abacia em estudo possui baixa capacidade de drenagem.

O índice de circularidade de $0,68 \mathrm{~km}$, indicando que o perímetro da bacia aproxima-se a um círculo, favorecendo os processos de inundação (cheias rápidas), pois há maiores possibilidades de chuvas intensas ocorrerem simultaneamente em toda sua extensão, concentrando grande volume de água no tributário principal (CARDOSO et al., 2006). O Índice de sinuosidade próximo a 1 indica que os canais tendem a serem retilíneos, já os valores superiores a 2,0, indicam que os canais tendem a ser tortuosos e os valores intermediários indicam formas transicionais, regulares e irregulares, sendo o da bacia estudado, de $1,12 \mathrm{~km}$.

\section{CONSIDERAÇÕES FINAIS}




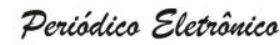 Fórum Ambiental \\ da Alta Paulista

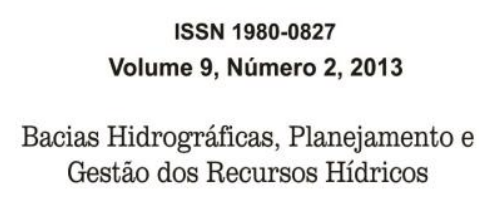

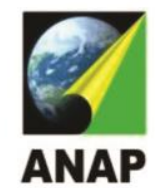

O estudo de análises morfométricas da microbacia do Córrego do Vangasse resultou em índices morfométricos de poucas tendências a enchentes, desconsiderando ocorrências anormais de precipitação. Os parâmetros de drenagem apresentam sinuosidade mediana dos canais, o que pode ser indicativo de um escoamento mais lento. Desta forma, pode-se afirmar que a análise morfométrica apresentou resultados que facilitaram a compreensão de forma integrada de diversos aspectos da área em estudo. O uso de ferramentas SIG e geoprocessamento é essencial para o planejamento e gestão dos recursos hídricos já que eles subsidiam análises e estudos ambientais.

\section{REFERÊNCIAS}

ANTONELI, V.; THOMAZ, E.L. Caracterização do meio físico da bacia do Arroio Boa Vista, Guamiranga-PR. Rev. Caminhos da Geografia, Uberlândia, v.8, n.21, p46-58, jun. 2007.

CARDOSO, L. G. Características Físicas de Bacias Hidrográficas: Alguns Índices. Material de aula da disciplina "Avaliação e Uso de Bacias Hidrográficas" - Curso de Pós Graduação em Agronomia - Energia na Agricultura da UNESP - Faculdade de Ciências Agronômicas (UNESP/FCA) 2012.

CARDOSO, C.A. et al. Caracterização morfométrica da bacia hidrográfica do rio Debossan, Nova Friburgo-RJ. Árvore, Viçosa, v.30, n.2, p.241-248, 2006.

CHRISTOFOLETTI, A. Geomorfologia. 2 ed. São Paulo: Edgard Blücher, 1974. 150p.

CRISTOFOLETTI, A. Análise morfométrica de bacias hidrográficas. Rev. Geomorfol, Campinas, v.18, n.9, p.35-64, 1969.

LIMA, W. P. Hidrologia Florestal Aplicada ao Manejo de Bacias Hidrográficas.

Escola Superior de Agricultura "Luiz de Queiroz" Departamento de Ciências Florestais Piracicaba - São Paulo. Piracicaba, 2008.

POLITANO, W.; PISSARRA, T.C.T. Relações entre características morfométricas quantitativas e estimativas da vazão em função da área em microbacias hidrográficas de $2^{\mathrm{a}}$ ordem de magnitude. Revista de Engenharia Agrícola, Jaboticabal, SP, v.23, n.1, p.179-186, 2003. 
SIQUEIRA, H. E. Análise Morfométrica e Definição do Potencial de uso do Solo da Microbacia do Rio Veríssimo, Veríssimo - MG. Enciclopédia Biosfera, Centro Científico Conhecer, Goiânia, v.8, n.15; p. 2012

VILLELA, S.M.; MATTOS, A. Hidrologia aplicada. São Paulo: McGRAWHill do Brasil, 1975. 245p. 